\title{
Imagen fotoperiodística de los líderes políticos en campaña electoral: encuadre, escenografía y gestualidad
}

\author{
Photojournalistic image of political leaders in election campaigs: framing, scenery and gestures
}

\author{
Joaquín B. LÓPEZ DEL RAMO \\ Universidad Rey Juan Carlos, C/Paseo del Molino S/N, 28943 Fuenlabrada (Madrid), \\ joaquin.lopezdelramo@urjc.es
}

\begin{abstract}
Resumen
Análisis de la imagen de los líderes políticos en campaña electoral de 2004 a través de las fotografías publicadas en los diarios Abc, El Mundo, El País y La Razón. El objetivo básico es cuantificar y comparar la presencia fotográfica de los principales líderes políticos y el tratamiento de la misma en cada medio. Se realiza un análisis de contenido sobre 257 imágenes, cuyos resultados indican predominio de los planos cortos, impresión gestual con connotaciones optimistas, una escenografía identificable de situaciones electorales, y un tratamiento cualitativo de de la imagen bastante similar en los diarios estudiados. Las principales conclusiones son: a) Se muestra una imagen estereotipada y previsible del político en campaña electoral. b) La escenografía contextualiza y enfatiza la imagen del líder. c) Hay una tendencia a primar la imagen del líder con mayor afinidad ideológica en algunos medios.
\end{abstract}

Palabras clave: Fotoperiodismo. Campaña electoral. Líderes políticos. Elecciones 2004. Análisis de contenido. Codificación fotográfica.

\section{Introducción}

Este trabajo se enmarca dentro del proyecto I+D "Política, información y ciudadanía en campaña electoral", desarrollado desde el departamento de Ciencias de la Comunicación 2 de la URJC, que aborda de manera integral el análisis informativo de las elecciones generales españolas del año 2004.

La importancia informativa de la fotografía periodística, sobradamente refrendada desde el punto de vista doctrinal, lo está también empíricamente, como ponen de manifiesto los trabajos de Küpfer (1991, p. 4) sobre áreas de atención en la lectura de los periódicos alemanes, que demuestran, por un lado, el poder captador de la fotografía hacia la lectura de los textos y, por otro, la superioridad de la imagen en cuanto a rapidez de comprensión y memorización por parte del lector.

\begin{abstract}
Image analysis of the political leaders in election campaign in 2004 through the published photographies in the newspapers Abc, El Mundo, El País and La Razón. The main objective is to compare and to quantify the photographic presence of the main political leaders and the treatment of it in each mass media. An analysis of content of 267 images is carried out, and the result shows predominance of close-ups, gesture impression with optimistic connotations, an identifiable scenery of election situations, and an qualitative treatment of the image quite similar in the newspapers analysed. The main conclusions are: a) a stereotyped and foreseeable image of the political leader in election campaign is shown, b) the scenery contextualises and emphasizes the image of the political leader, c) there is a tendency to predominate the image of the political leader with more ideological affinity in some mass media.
\end{abstract}

Keywords: Photojournalism. Election campaign. Political leaders. Elecctions 2004. Content analysis. Photographic coding.

En términos de contenido informativo, siguiendo a Barthes (1986, p. 11), la fotografía aporta un conjunto de datos (muchos de ellos valorativos), codificados y plasmados de manera autónoma, conformando una estructura independiente, aunque complementaria de la textual. En la misma línea, según lo indicado por Coleman (2002) — citada por Muñiz, Igartua y Otero (2006, p. 104) - las fotografías periodísticas pueden ejercer por sí mismas sobre el público lector efectos cognitivos y afectivos específicos. La relevancia especial que tienen los procesos electorales en el ámbito de la información política, constada por Esteve y Fernández del Moral (1999, p. 68), otorga a la fotografía periodística de esta temática mayor peso específico, circunstancia que, junto a las premisas anteriores, dan justificación de este trabajo.

El análisis realizado se orienta en torno a cuatro objetivos específicos: a) cuantificar el grado de 
presencia fotográfica de los diferentes líderes políticos; b) determinar y analizar los rasgos expresivos predominantes, a través de los cuales de transmite una determinada imagen del líder; c) averiguar si las fotografías publicadas en prensa reproducen los estereotipos y patrones de imagen genéricos comúnmente considerados como propios del político en campaña electoral; d) comparar las características de la codificación fotográfica realizada por diferentes medios a cada uno de los líderes en función de su adscripción ideológica.

\section{Metodología}

Se realiza el estudio de la totalidad de fotografías informativas cuyos protagonistas son los líderes de los tres principales partidos españoles (PSOE, PP e IU), publicadas en informaciones sobre la campaña electoral en cualquier sección del periódico (además de la portada) durante el periodo comprendido entre el 22 de febrero al 11 de marzo de 2004. La muestra está integrada por 257 imágenes, que se definen como unidad de análisis. Dicha muestra fue extraída de un universo compuesto por 530 fotografías, que abarca todas las publicadas sobre la campaña de las elecciones legislativas de 2004, entre las que se seleccionan para este trabajo únicamente aquellas (las 257 indicadas) cuyos actantes principales son Mariano Rajoy, Rodríguez Zapatero y Gaspar Llamazares.

Coincidiendo con Zunzunegui (1998, p. 139), en el caso de la fotografía de prensa no puede obviarse que existen formas de tratamiento del texto visual, debidas a la codificaciónmanipulación realizada por el fotógrafo, que influyen claramente en el nivel de contenido. Dichas operaciones codificadoras han sido sistematizadas por Alonso Erusquin (1995, p. 106), de quien este trabajo toma tres categorías específicamente relacionadas con los objetivos de la investigación: código espacial, código gestual y código escenográfico.

Desde el punto de vista del diseño metodológi$\mathrm{co}$, se realiza un análisis de contenido en el que son considerados dos tipos de datos generales: a) rasgos documentales básicos de la imagen (valores denotativos), y b) rasgos de codificación fotográfica (valores connotativos). El instrumento para el estudio de cada unidad de análisis es una matriz compuesta por un conjunto de indicadores específicos, para cuya elaboración se han tomado como base los modelos de estudio documental y de contenido de la fotografía de prensa de Vilches (1987), Abreu (1993), Rodríguez Merchán (1993), Sousa (1998) y, especialmente, Alonso Erusquin (ibi- dem). La ficha de análisis está descrita en la tabla I.

\begin{tabular}{|c|c|}
\hline \multicolumn{2}{|c|}{ 1. Indicadores de Atributos documentales } \\
\hline Indicador & Descripción \\
\hline 1.1. Protagonista & Identificación del mismo \\
\hline 1.2. Medio & $\begin{array}{l}\text { Abc, El Mundo, El País o } \\
\text { La Razón }\end{array}$ \\
\hline \multicolumn{2}{|c|}{ 2. Indicadores de Codificación fotográfica } \\
\hline Indicador & Descripción \\
\hline 2.1 Encuadre. & $\begin{array}{l}\text { Campo de visión captado: } \\
\text { general, grupal o corto }\end{array}$ \\
\hline 2.2. Verticalidad & $\begin{array}{l}\text { Captación en picado o } \\
\text { contrapicado }\end{array}$ \\
\hline 2.3. Impresión gestual & $\begin{array}{l}\text { Gestualidad que muestra } \\
\text { el protagonista principal }\end{array}$ \\
\hline 2.4. Escenografía & $\begin{array}{l}\text { Entorno, elementos de } \\
\text { ambiente, vestuario }\end{array}$ \\
\hline
\end{tabular}

Tabla I. Indicadores de la ficha de análisis

Sobre los datos extraídos, y tomando la referencia de Igartua (2007), se lleva a cabo una exploración de tipo univariado, que permite la obtención de frecuencias y porcentajes de los distintos indicadores individuales, y un análisis bivariable/multivariable para examinar la correlación entre indicadores de especial significado.

\section{Resultados}

3.1. Análisis univariado: frecuencia y porcentaje de indicadores individuales

\subsubsection{Rasgos documentales (denotativos)}

Protagonista principal. Se toma como protagonista principal a la persona de mayor relevancia política, o bien a la que ocupa una posición preeminente en la toma. Como se recoge en la Tabla II, el líder con mayor frecuencia de aparición es Mariano Rajoy, a quien corresponde un total de 118 imágenes, equivalentes a un porcentaje del $45,9 \%$ respecto al total de la muestra analizada. Le sigue Rodríguez Zapatero, que es actante principal en 97 fotos, lo que representa un $37,8 \%$, y Gaspar Llamazares, con 42 imágenes, un $16,3 \%$ de la muestra.

\begin{tabular}{lrr}
\hline Lider & Frecuencia & $\%$ \\
\hline Rajoy & 118 & $45,9 \%$ \\
Podríguez Zapatero & 97 & $37,8 \%$ \\
Llamazares & 42 & $16,3 \%$ \\
\hline Total & 257 & \\
\hline
\end{tabular}

Tabla II. Frecuencia y porcentaje de fotografías por líder 
Medio. Se estudian los cuatro diarios de información general y difusión nacional publicados durante las elecciones generales de 2004. El diario que más fotografías de líderes publica es La Razón, seguido, por este orden, de El País, El Mundo y Abc. Los repartos de frecuencias y porcentajes figuran en la Tabla VI.

\begin{tabular}{|l|l|c|c|}
\hline Periódico & Líder & Frecuencia & $\%$ \\
\hline \multirow{2}{*}{$\begin{array}{l}\text { Abc } \\
\text { Total:49 }\end{array}$} & Rajoy & 23 & 46,9 \\
\cline { 2 - 4 }$(19,1 \%)$ & Zapatero & 20 & 40,8 \\
\cline { 2 - 4 } & Llamazares & 6 & 12,3 \\
\hline La Razón & Rajoy & 44 & 53,6 \\
\cline { 2 - 4 } Total:82 & Zapatero & 27 & 33 \\
\cline { 2 - 4 }$(31,9 \%)$ & Llamazares & 11 & 13,4 \\
\hline El Mundo & Rajoy & 25 & 43,1 \\
\cline { 2 - 4 } Total:58 & Zapatero & 21 & 36,2 \\
\cline { 2 - 4 }$(22,5 \%)$ & Llamazares & 12 & 20,7 \\
\hline \multirow{2}{*}{$\begin{array}{l}\text { El País } \\
\text { Total:68 } \\
26,5 \%\end{array}$} & Rajoy & 26 & 38,2 \\
\cline { 2 - 4 } & Zapatero & 29 & 42,6 \\
\cline { 2 - 4 } & Llamazares & 13 & 19,2 \\
\hline
\end{tabular}

Tabla III. Frecuencia y porcentaje de fotografías por líderes/periódicos

\subsubsection{Rasgos de codificación fotográfica (con- notativos)}

Encuadre. Este indicador pertenece, según Alonso (ibidem, p. 107), a la codificación espacial, y está directamente relacionado con el concepto de cuadro o campo, entendido como porción de espacio más o menos amplia que el fotógrafo selecciona y es abarcado por el ojo de la cámara. Dentro de la clasificación tradicional de los encuadres, aquí se contemplan tres grandes categorías de encuadres: generales, grupales y cortos. Los resultados obtenidos (tabla IV) muestran un claro predominio de los planos cortos, categoría en la que se incluye el $67,8 \%$ de las fotografías. Los encuadres generales se dan en el $19,8 \%$ y los grupales en el
$12,45 \%$ del total de fotos analizadas. No se han apreciado aspectos significativos relacionados con la distorsión de la imagen que produce la angulación forzada de la toma con ópticas de tipo gran angular y teleobjetivo.

Verticalidad. Dentro de los aspectos de codificación espacial, el nivel desde el que se efectúa la toma (plano picado o contrapicado) proporcionan una visión que, respectivamente, minusvalora o ensalza al personaje captado (Alonso, ididem p. 115). El uso global de este recurso se produce en el $19,5 \%$ de las fotografías de los líderes (50 imágenes), lo que, de manera desglosada, equivale al $15,6 \%$ de las fotografías captadas en plano contrapicado (40 imágenes) y el 3,9\% en plano picado (10 imágenes).

Impresión gestual. Los gestos y posiciones físicas de los actantes poseen una particular importancia connotativa en la fotografía periodística. Según Alonso (ibidem, p. 121), al congelar un instante concreto, y con él nuestra visión, la fotografía destaca de manera suprema, y a veces desajustada, un aspecto de los hechos por encima de los demás, pudiendo producir un efecto caricaturizador de los personajes. La gran variedad de gestos o posturas que reflejan estados de ánimo o actitudes ha sido estudiada y recopilada de forma muy pormenorizada por varios investigadores. Tomando a Flora Davis (2005) como referente básico, y dada la amplitud e interés de la cuestión, en aras a la necesaria concreción se han considerado en este análisis 29 categorías gestuales, a saber: tranquilidad, accidental (pillado), despiste, apelación, reivindicación, sorpresa, alegría, enfadotensión, tristeza, indiferencia, superioridad, preocupación, maquinación, desconfianza, confianza, cansancio, hipocresía, abatimiento, desprecio, ira, falsedad, seriedad, cercanía, neutro, reflexiva, informalidad, miedodolor, respeto, y mando o jerarquía.

\begin{tabular}{|l|c|c|c|c|c|c|}
\cline { 2 - 7 } \multicolumn{1}{c|}{} & \multicolumn{2}{c|}{ General } & \multicolumn{2}{c|}{ Grupal } & \multicolumn{2}{c|}{ Corto } \\
\cline { 2 - 7 } \multicolumn{1}{c|}{} & Fr. & $\%$ & Fr. & $\%$ & Fr. & $\%$ \\
\hline Abc & 8 & 16,3 & 6 & 12,3 & 35 & 71,4 \\
\hline La Razón & 16 & 19,5 & 2 & 2,4 & 64 & 78,1 \\
\hline El Mundo & 9 & 15,5 & 7 & 12,1 & 42 & 72,4 \\
\hline El País & 18 & 26,5 & 17 & 25 & 33 & 48,5 \\
\hline Totales & 51 & $19,8(2)$ & 32 & 12,45 & 174 & 67,8 \\
\hline
\end{tabular}

Tabla IV. Frecuencia y porcentaje de encuadres

Los resultados obtenidos se plasman en la tabla $V$, y muestran que la gestualidad reflejada con mayor frecuencia en las fotografías de los líderes políticos es la alegría o satisfacción $(36,2 \%)$, seguida por la gestualidad neutra $(15,5 \%) \mathrm{y}$, con una frecuencia mucho menor, el resto de categorías. En términos generales, se constata el predomino de gestos con connotaciones positivas (confianza, cercanía, etc.) y de los rasgos neutros sobre los negativos. Aunque la frecuen- 
cia no es elevada, cabe mencionar por su significación subjetiva la publicación de fotografías de líderes que muestran gestos accidentales poco favorecedores o ridiculizantes.

\begin{tabular}{lcc}
\hline Categoría & Frecuencia & Porcentaje \\
\hline Tranquilidad & 7 & 2,7 \\
Accidental & 16 & 6,2 \\
Despiste & 1 & 0,4 \\
Apelación & 24 & 9,3 \\
Reivindicación & 3 & 1,2 \\
Sorpresa & 1 & 0,4 \\
Alegría & 93 & 36,2 \\
Enfado & 1 & 0,4 \\
Tensión & 2 & 0,8 \\
Tristeza & - & - \\
Indiferencia & - & - \\
Superioridad & 6 & 2,3 \\
Preocupación & 1 & 0,4 \\
Maquinación & 1 & 0,4 \\
Desconfianza & 7 & 2,7 \\
Confianza & 1 & 0,4 \\
Cansancio & 1 & 0,4 \\
Hipocresía & - & - \\
Abatimiento & - & - \\
Desprecio & - & - \\
Ira & - & - \\
Falsedad & 18 & 7,1 \\
Seriedad & 21 & 8,2 \\
Cercanía & 40 & 15,5 \\
Neutro & 12 & 4,7 \\
Reflexiva & - & - \\
Informalidad & - & - \\
Miedo-dolor & - & - \\
Respeto & 1 & 0,4 \\
Mando- jerarquía & - & - \\
\hline
\end{tabular}

Tabla V. Frecuencia y porcentaje de gestualidad

Escenografía. A través de la codificación escenográfica (en la que se incluyen entorno, decorado y vestuario) se transmiten valores connotativos como el realce o minimización de los personajes, la identificación de protagonistas con determinados colectivos o situaciones, su nivel o estatus, etc. Las categorías consideradas en este apartado del análisis figuran en la primera columna de la tabla VI.

En el recuento y valoración de los resultados (Tabla VI) debe tenerse en cuenta que no todas las fotografías muestran rasgos escenográficos claros, por ejemplo, las que poseen encuadre muy corto (primeros planos muy acentuados o planos-detalle) y, por otra parte, la posibilidad de que una misma foto tenga simultáneamente varios encuadres escenográficos. El valor escenográfico predominante es la identificación de partido, que está presente en el $30 \%$ de las fotografías de los líderes (77 imágenes), segui- do del 10 (Identificación de la situación), observable en un $15,6 \%$ de las fotos (40 imágenes). Las dos siguientes categorías más frecuentes son realce del personaje y realce masivo, con el 12,4 y el $7,4 \%$ respectivamente.

\begin{tabular}{lcc}
\hline Rasgo & Frecuencia & Porcentaje \\
\hline Identificación de partido & 77 & 30 \\
Realce personajes & 32 & 12,4 \\
Realce masivo & 19 & 7,4 \\
Minimiza personas & & - \\
Localización Geográfica & 1 & 0,4 \\
Climatología & 1 & 0,4 \\
Identificación de cargo & - & - \\
Identificación de rol & 4 & 1,5 \\
Identificación de status & 16 & 6,2 \\
Identificación por la situación & 40 & 15,6 \\
Ahogo/opresión & 1 & 0,4 \\
Libertad & - & - \\
Ambiente de modernidady & - & - \\
Disfraz & 5 & 1,9 \\
\hline
\end{tabular}

Tabla VI. Categorías escenográficas

\subsection{Análisis bivariable y multivariable}

\subsubsection{Presencia de líderes por diarios (análisis} bivariable)

\begin{tabular}{|c|c|c|c|c|c|c|c|}
\hline & \multicolumn{2}{|c|}{ General } & \multicolumn{2}{|c|}{ Grupal } & \multicolumn{2}{|c|}{ Corto } \\
\hline & & Fr. & $\%$ & $F r$. & $\%$ & Fr. & $\%$ \\
\hline \multirow{3}{*}{$\begin{array}{l}A b c \\
\text { Total:49 } \\
(19,1 \%)\end{array}$} & Rajoy & 4 & 8,2 & 4 & 8,2 & 15 & 30,6 \\
\hline & Zapatero & 4 & 8,2 & 1 & 2,1 & 15 & 30,6 \\
\hline & Llamazares & - & - & 1 & 2,1 & 5 & 10,2 \\
\hline \multirow{3}{*}{$\begin{array}{l}\text { La } \\
\text { Razón } \\
\text { Total:82 } \\
(31,9 \%)\end{array}$} & Rajoy & 12 & 14,6 & 1 & 1,2 & 31 & 37,8 \\
\hline & Zapatero & 4 & 4,9 & 1 & 1,2 & 22 & 26,8 \\
\hline & Llamazares & - & - & - & - & 11 & 13,4 \\
\hline \multirow{3}{*}{$\begin{array}{l}\text { El } \\
\text { Mundo } \\
\text { Total:58 } \\
(22,5 \%) \\
\end{array}$} & Rajoy & 4 & 6,9 & 2 & 3,4 & 19 & 32,7 \\
\hline & Zapatero & 4 & 6,9 & 4 & 6,9 & 13 & 22,4 \\
\hline & Llamazares & 1 & 1,7 & 1 & 1,7 & 10 & 17,2 \\
\hline \multirow{3}{*}{$\begin{array}{l}\text { El País } \\
\text { Total:68 } \\
26,5 \%\end{array}$} & Rajoy & 7 & 10,2 & 9 & 13,2 & 10 & 14,7 \\
\hline & Zapatero & 8 & 11,7 & 4 & 5,9 & 17 & 25 \\
\hline & Llamazares & 3 & 4,4 & 4 & 5,9 & 6 & 8,8 \\
\hline
\end{tabular}

Tabla VIII. Frecuencia y porcentaje de encuadres por líderes y diarios respecto al total de fotos

En la Tabla VII se cruzan los datos de los indicadores Líder y Medio. Los periódicos que más fotografías publican son, por este orden, $\mathrm{La}$ Razón, seguido de El País, El Mundo y Abc. Se constata que Rajoy es el personaje del que se publican más fotografías en todos los diarios, salvo El País, donde lo es Rodríguez Zapatero. El líder de IU es el tercero por frecuencia de aparición en todos los diarios. La mayor diferencia en el número de fotos de los líderes del PP y 
el PSOE se aprecia en La Razón, con casi 20 puntos a favor del primero, mientras que en resto de diarios la diferencia es mucho más corta. Llamazares ocupa en todas la cabeceras el tercer puesto, siendo mayor el porcentaje de fotografías del mismo en El Mundo y El País que en $A b c$ y La Razón.

\subsubsection{Tratamiento de encuadres por líderes y} diarios (análisis multivariable).

El predominio del plano corto se observa por igual en los cuatro diarios analizados (Tabla VIII), de forma más acusada en La Razón y menos en El País, diario cuyas fotos presentan encuadres más abiertos. La tónica general anterior es común en las fotos de todos los líderes, aunque varía el grado de "acercamiento" que de éstos muestran los diferentes periódicos (Tabla VII). Así, Rajoy presenta una visión más lejana en El País, y más cercana (por cantidad de planos cortos) en las páginas de El Mundo. El porcentaje de fotos en plano corto del líder del PP con respecto a su directo competidor electoral, Rodríguez Zapatero, es mayor en El Mundo y La Razón, idéntico en Abc y menor en El País, donde el socialista presenta mayor frecuencia de encuadres cortos que los otros líderes.

\subsubsection{Tratamiento de la verticalidad por líderes y diarios (análisis multivariable).}

Los resultados que recogidos en la Tabla IX indi can que hay un predominio del empleo de planos contrapicados frente a los picados en todos diarios. Considerados comparativamente, el diario que más emplea este recurso es El Mundo, seguido de El País, La Razón y Abc. Si se contemplan las cifras tomando los diarios como variable independiente y los líderes como dependiente, se aprecian grandes desigualdades, pues no hay una tendencia homogénea ni definida en ningún sentido, aunque se aprecia que Rajoy es el líder que más veces es captado con este tipo de angulaciones verticales.

\begin{tabular}{|l|l|c|c|c|c|}
\cline { 3 - 6 } \multicolumn{2}{c|}{} & \multicolumn{2}{c|}{ Picado } & \multicolumn{2}{c|}{ Contrapicado } \\
\cline { 3 - 6 } \multicolumn{2}{c|}{} & $F$ & $\%$ & $F$ & $\%$ \\
\hline \multirow{3}{*}{ Abc } & Rajoy & - & - & 5 & 21,7 \\
\cline { 2 - 6 } & Zapatero & 1 & 5 & - & - \\
\cline { 2 - 6 } & Llamazares & - & - & - & - \\
\hline \multirow{3}{*}{ La Razón } & Rajoy & 3 & 6,8 & 8 & 18,1 \\
\cline { 2 - 6 } & Zapatero & - & - & 3 & 11,1 \\
\cline { 2 - 6 } & Llamazares & - & - & 1 & 9 \\
\hline \multirow{3}{*}{ El Mundo } & Rajoy & 3 & 12 & 1 & 4 \\
\cline { 2 - 6 } & Zapatero & 1 & 4,7 & 5 & 23,8 \\
\cline { 2 - 6 } & Llamazares & 1 & 3,8 & 7 & 26,9 \\
\hline \multirow{3}{*}{ El País } & Rajoy & 1 & 3,8 & 7 & 26,9 \\
\cline { 2 - 6 } & Zapatero & - & - & 2 & 6,8 \\
\cline { 2 - 6 } & Llamazares & - & - & 1 & 7,6 \\
\hline Totales & \multicolumn{2}{|c|}{10} & 3,9 & 40 & 15,6 \\
\hline
\end{tabular}

Tabla IX. Frecuencia y porcentaje de verticalidad por líderes y diarios (Porcentajes respecto al total de fotos de cada líder en ese diario).

\subsubsection{Gestualidad por líderes y diarios (análisis multivariable)}

En todos los diarios predominan los gestos que transmiten alegría o satisfacción; el segundo tipo gestual más reiterado es el neutro, salvo en El Mundo, que es la amabilidad o cercanía. Los líderes del PP y del PSOE presentan el mismo número de tipologías gestuales (14 tipos), mientras que Llamazares muestra 10, en consonancia con su menor número de fotos.

\begin{tabular}{|c|c|c|c|c|c|c|c|c|c|c|}
\hline \multirow{2}{*}{ Gestualidad } & \multicolumn{2}{|c|}{$A b c$} & \multicolumn{2}{|c|}{ La Razón } & \multicolumn{2}{|c|}{ El Mundo } & \multicolumn{2}{|c|}{ El País } & \multicolumn{2}{|c|}{ Globales } \\
\hline & Fr. & $\%$ & Fr. & $\%$ & Fr. & $\%$ & Fr. & $\%$ & Fr. & $\%$ \\
\hline Tranquilidad & 1 & 4,3 & 3 & 6,8 & - & - & 1 & 3,8 & 5 & 4,2 \\
\hline Accidental & 2 & 8,7 & 1 & 2,3 & 4 & 16 & 7 & 26,9 & 14 & 11,8 \\
\hline Despiste & - & - & - & - & - & - & 1 & 3,8 & 1 & 0,8 \\
\hline Apelación & 4 & 17,4 & 1 & 2,3 & 3 & 12 & 2 & 7,7 & 19 & 7,6 \\
\hline Alegría & 10 & 43,4 & 16 & 36,3 & 5 & 20 & 5 & 19,2 & 36 & 30,5 \\
\hline Preocupación & - & - & 1 & 2,3 & - & - & 1 & 3,8 & 2 & 1,7 \\
\hline Desconfianza & - & - & 1 & 2,3 & - & - & - & - & 1 & 0,8 \\
\hline Confianza & - & - & - & - & 2 & 8 & - & - & 2 & 1,7 \\
\hline Cansancio & - & - & 1 & 2,3 & - & - & - & - & 1 & 0,8 \\
\hline Seriedad & 1 & 4,3 & 4 & 9,1 & 4 & 16 & - & - & 9 & 7,6 \\
\hline Cercanía & - & - & - & - & 4 & 16 & 3 & 11,5 & 7 & 5,9 \\
\hline Neutro & 3 & 13,1 & 15 & 34,1 & 1 & 4 & 5 & 19,2 & 24 & 20,3 \\
\hline Reflexiva & 2 & 8,7 & 1 & 2,3 & 1 & 4 & 1 & 3,8 & 3 & 2,5 \\
\hline Mando & - & - & - & - & 1 & 4 & - & - & 1 & 0,8 \\
\hline Total & & 3 & & & & & & 26 & & 18 \\
\hline
\end{tabular}

Tabla X. Frecuencia y porcentaje rasgos gestuales por diarios. Líder: M. Rajoy 


\begin{tabular}{|c|c|c|c|c|c|c|c|c|c|c|}
\hline \multirow{2}{*}{ Gestualidad } & \multicolumn{2}{|c|}{$A b c$} & \multicolumn{2}{|c|}{ La Razón } & \multicolumn{2}{|c|}{ El Mundo } & \multicolumn{2}{|c|}{ El País } & \multicolumn{2}{|c|}{ Globales } \\
\hline & Fr. & $\%$ & Fr. & $\%$ & Fr. & $\%$ & Fr. & $\%$ & Fr. & $\%$ \\
\hline Tranquilidad & 1 & 5 & 1 & 3,7 & - & - & - & - & 2 & 2,1 \\
\hline Accidental & - & - & - & 0 & - & - & 2 & 6,9 & 2 & 2,1 \\
\hline Apelación & 1 & 5 & 2 & 7,4 & 1 & 4,7 & 4 & 13,7 & 8 & 8,2 \\
\hline Alegría & 14 & 70 & 14 & 51,8 & 10 & 47,6 & 7 & 24,2 & 45 & 46,3 \\
\hline Enfado-Tensión & - & - & - & - & 1 & 4,7 & - & - & 1 & 1,1 \\
\hline Tristeza & 1 & 5 & - & - & - & - & - & - & 1 & 1,1 \\
\hline Preocupación & - & - & 2 & 7,4 & - & - & - & - & 2 & 2,1 \\
\hline Maquinación & - & - & 1 & 3,7 & - & - & - & - & 1 & 1,1 \\
\hline Confianza & - & - & - & - & 2 & 9,5 & 3 & 10,3 & 5 & 5,1 \\
\hline Hipocresía & - & - & 1 & 3,7 & - & - & - & - & 1 & 1,1 \\
\hline Seriedad & - & - & 1 & 3,7 & 1 & 4,7 & 3 & 10,3 & 5 & 5,1 \\
\hline Cercanía & 1 & 5 & - & - & 4 & 19,1 & 5 & 17,2 & 9 & 9,3 \\
\hline Neutro & 1 & 5 & 5 & 18,5 & - & - & 4 & 13,7 & 10 & 10,3 \\
\hline Reflexiva & 1 & 5 & - & - & 2 & 9,5 & 1 & 2,4 & 4 & 4,1 \\
\hline Total & \multicolumn{2}{|c|}{20} & \multicolumn{2}{|c|}{27} & \multicolumn{2}{|c|}{21} & \multicolumn{2}{|c|}{29} & \multicolumn{2}{|c|}{97} \\
\hline
\end{tabular}

Tabla XI. Frecuencia y porcentaje rasgos gestuales por diarios. Líder: J. L. Rodríguez Zapatero

\begin{tabular}{|c|c|c|c|c|c|c|c|c|c|c|}
\hline \multirow{2}{*}{ Gestualidad } & \multicolumn{2}{|c|}{$A b c$} & \multicolumn{2}{|c|}{ La Razón } & \multicolumn{2}{|c|}{ El Mundo } & \multicolumn{2}{|c|}{ El País } & \multicolumn{2}{|c|}{ Globales } \\
\hline & $F r$. & $\%$ & Fr. & $\%$ & Fr. & $\%$ & Fr. & $\%$ & Fr. & $\%$ \\
\hline Apelación & 1 & 16,6 & 1 & 9 & - & - & 4 & 30,7 & 6 & 14,3 \\
\hline Reivindicación & - & - & - & - & 3 & 25 & - & - & 3 & 7,1 \\
\hline Sorpresa & - & - & 1 & 9 & - & - & - & - & 1 & 2,3 \\
\hline Alegría & 3 & 50 & 1 & 9 & 3 & 25 & 5 & 38,5 & 12 & 28,6 \\
\hline Tristeza & - & - & 1 & 9 & - & - & - & - & 1 & 7,1 \\
\hline Preocupación & - & - & 2 & 18 & - & - & - & - & 2 & 4,7 \\
\hline Seriedad & 1 & 16,6 & - & - & 2 & 16,6 & 1 & 7,6 & 4 & 9,5 \\
\hline Cercanía & 1 & 16,6 & - & - & 2 & 16,6 & 1 & 7,6 & 4 & 9,5 \\
\hline Neutro & - & - & 5 & 45,5 & - & - & 1 & 7,6 & 6 & 14,3 \\
\hline Reflexiva & - & - & - & - & 2 & 16,6 & 1 & 7,6 & 3 & 7,1 \\
\hline Total & \multicolumn{2}{|c|}{6} & \multicolumn{2}{|c|}{11} & \multicolumn{2}{|c|}{12} & \multicolumn{2}{|c|}{13} & \multicolumn{2}{|c|}{42} \\
\hline
\end{tabular}

Tabla XII. Frecuencia y porcentaje rasgos gestuales por diarios. Líder: G. Llamazares

\begin{tabular}{|c|c|c|c|c|c|c|c|c|c|c|}
\hline \multirow{2}{*}{ Escenografía } & \multicolumn{2}{|c|}{$A b c$} & \multicolumn{2}{|c|}{ La Razón } & \multicolumn{2}{|c|}{ El Mundo } & \multicolumn{2}{|c|}{ El País } & \multicolumn{2}{|c|}{ Globales } \\
\hline & Fr. & $\%$ & Fr. & $\%$ & Fr. & $\%$ & Fr. & $\%$ & Fr. & $\%$ \\
\hline Identificación de partido & 8 & 34,7 & 10 & 22,7 & 10 & 40 & 6 & 23,1 & 34 & 28,8 \\
\hline Realce personajes & 6 & 26,1 & 2 & 4,5 & 4 & 16 & 3 & 11,5 & 15 & 12,7 \\
\hline Realce masivo & 1 & 4,3 & 3 & 6,8 & 5 & 20 & 2 & 7,7 & 11 & 9,3 \\
\hline Localización Geográfica & - & - & - & - & 1 & 4 & - & - & 1 & 0,8 \\
\hline Identificación de rol & - & - & - & - & 1 & 4 & - & - & 1 & 0,8 \\
\hline Identificación de status & 1 & 4,3 & - & - & 5 & 20 & 4 & 15,4 & 10 & 8,4 \\
\hline Identificación por la situación & 4 & 17,4 & 10 & 22,7 & 3 & 12 & 5 & 19,2 & 22 & 18,6 \\
\hline Ahogo/opresión & - & - & - & - & 1 & 4 & - & - & 1 & 0,8 \\
\hline Disfraz. & - & - & - & - & 4 & 16 & - & - & 4 & 3,4 \\
\hline Total & \multicolumn{2}{|c|}{23} & \multicolumn{2}{|c|}{44} & \multicolumn{2}{|c|}{25} & \multicolumn{2}{|c|}{26} & \multicolumn{2}{|c|}{118} \\
\hline
\end{tabular}

Tabla XIII. Frecuencia y porcentaje rasgos escenográficos por diarios. Líder: M. Rajoy

Por líderes, la satisfacción es el gesto predominante del Rajoy (Tabla IX) en todos los diarios, salvo El País, donde en las fotos de este político dominan los gestos accidentales con carga subjetivizadora negativa. La satisfacción es la cate- goría gestual más amplia con que aparece Rodríguez Zapatero en todos los periódicos (Tabla X), seguido por el gesto neutro y la cercanía, salvo en La Razón, que es la hipocresía. El líder socialista presenta en general una ges- 
tualidad más homogénea y alegre que Rajoy. La imagen gestual de Llamazares (Tabla XI) muestra un perfil más heterogéneo y difuso.

\subsubsection{Escenografía por líderes y diarios (análi- sis multivariable).}

Las fotografías de los cuatro diarios patentizan un tratamiento muy similar respecto a la escenografía. La identificación de partido y las situaciones características de una campaña electoral dominan en las fotos de los tres líderes. Las fotografías de Rajoy presentan 9 tipos de encuadres escenográficos, frente a los 7 de Rodríguez y los 5 de LLamazares. Aunque las diferencias porcentuales son cortas, el mayor grado de realce de Rajoy se observa en $A b c$ y $E l$ Mundo, y el realce de Rodríguez Zapatero es más acusado en El País y Abc.

\section{Conclusiones}

A partir de los anteriores resultados se pueden inferir las siguientes conclusiones:

1. Los líderes políticos muestran en general una visión cercana y poco distorsionada, marcando la sensación de proximidad al lector con el recurso mayoritario a los planos cortos.

2. Las fotografías transmiten en todos los diarios una gestualidad alegre, triunfal, donde predomina la seguridad, la cercanía y la satisfacción, y ello por igual en los líderes de los tres partidos. En dicho sentido puede afirmarse que se trata de una imagen estereotipada y previsible, por ser la convencionalmente transmitida y asumida en las campañas electorales.

3. La escenografía contribuye a reforzar la imagen del líder y sitúa inequívocamente los hechos en el contexto electoral al que pertenecen.

4. Las características connotativas de las fotografías de todos los líderes presentan notables similitudes en los cuatro diarios analizados, si bien se observa una cierta tendencia a primar la imagen del líder del PP en $\mathrm{La}$ Razón y $A b c$, y, de manera aún más acentuada, al líder del PSOE en El País.

\section{Recomendaciones}

A partir de este trabajo, podrían suscitarse alternativas investigación aún poco exploradas en fotoperiodismo, y más concretamente dentro de la temática político-electoral. Entre ellas se propone la realización de estudios comparados referidos a campañas electorales de países de nuestro ámbito geográfico o de otras zonas o continentes. Asimismo, se estima que podría tener interés la realización de trabajos de planteamiento histórico, para analizar el tratamiento de la fotografía periodística en diversas elecciones de diferentes épocas y contextos sociopolíticos.

\section{Notas}

En las tablas IX a XIV sólo se computan las categorias escenográficas que registran algún valor positivo, y los porcentajes se proporcionan respecto al total de fotos de todos los líderes en ese diario.

\section{Referencias}

Alonso Erusquin, Manuel (1995). Fotoperiodismo: formas y códigos. Madrid: Síntesis, 1995.

Barthes, Roland (1986). El mensaje fotográfico.// Lo obvio y lo obtuso. Barcelona-Buenos Aires: Paidos, 1986. 11-27.

Coleman, Renita (2002). The Effects of Visuals on Ethical Reasoning: What's a Photograph Worth to Journalists Making Moral Decisions. Comunicación presentada en la convención de la AEJMC, Miami (EEUU), 5-8- Agosto 2002.

Davis, Flora (2005). La comunicación no verbal. Madrid: Alianza, 2005

Esteve Ramírez. Francisco; Fernández del Moral, Javier (1999). Áreas de especialización Periodística. Madrid: Fragua, 1999.

Igartua, Juan.José (2007). Métodos cuantitativos de investigación en comunicación. Barcelona: Bosch, 2007.

Küpfer, N. (1991). Esa caprichosa mirada. // Revista de la Universidad Catolica de Chile. 7 (1991) 109-120.

Muñiz, C.; Igartua, J. J.; Otero, J. A. Imágenes de la inmigración a través de la fotografía de prensa: Un estudio de los principales periódicos españoles. // Comunicación y Sociedad. 19:1 (2006) 103-128.

Rodríguez Merchán, Eduardo (1993). La realidad fragmentada. Madrid: Editorial de la Universidad Complutense, 1993.

Sousa, Jose P. (1998). Fotojornalismo Preformativo (1998)., Oporto: Ediçoes Universidade Fernando Pessoa, 1998.

Vilches, Lorenzo (1987). Teoría de la imagen periodística. Barcelona: Paidós, 1987.

Zunzunegui, Santos (1998). Pensar la imagen, Madrid, Cátedra, $1998,4^{\mathrm{a} E d}$. 